\title{
A STUDY OF SOME FACTORS INFLUENCING THE STRENGTH AND STABILITY OF EXPERIMENTAL PA- PERS MADE FROM TWO DIFFERENT SULPHITE PULPS
}

\author{
By Royal H. Rasch, ${ }^{1}$ Merle B. Shaw, and George W. Bicking
}

\section{ABSTRACT}

A 5 study on a semicommercial scale was made at the Bureau of Standards of the manufacture of bond papers from pulps prepared commercially by the sulphite process. Two kinds of bleached sulphite pulp were used in these experiments; one was of domestic and the other of foreign manufacture. A series of 43 experimental papers was made from the pulps in which the variables of beating and sizing were studied.

Since this study was confined to the bond type of papers, in which strength is an important requirement, the beating treatment was conducted in such manner as to develop the maximum strength consistent with other desired properties. This was accomplished satisfactorily by means of a 4-hour beating in the case of one pulp, and a 5-hour beating in the case of the other. The beater roll was lowered gradually during the course of the beatings. The beaten stock was brushed lightly in the Jordan. In strength the experimental papers compared favorably with the average good grade of sulphite bond.

Papers made from either type of sulphite pulp underwent marked changes in properties when subjected to the accelerated aging test, which consists in heating the paper in air at $100^{\circ} \mathrm{C}$. for 72 hours. The moderate stability of the best papers produced as indicated by this test, was commensurate with the medium degree of fiber purity. While all the papers are relatively unstable, careful adjustment of the acidity of the rosin-sized papers resulted in marked improvement in stability without sacrifice of the degree of sizing. The correct adjustment of acidity appears to be at a pH of 5.0. It is indicated that the amount of rosin used in engine sizing the sulphite papers made was not an important consideration as far as the effect on their stability was concerned.

When unsized or rosin-sized papers were surfaced sized with glue or starch there was an improvement in tensile properties and a decrease in tearing strength in approximate proportion to the amount of size taken up by the basic paper. In general, no very marked increase in folding endurance resulted on surface sizing with either glue or starch. A glue-sized currency-type paper made from the stronger of the two fibers under study was of very high folding endurance, but not sufficiently so to meet the United States Government specification for this kind of paper. In general, glue sizing improved slightly the stability of the papers. It was indicated that for optimum stability the alum in the tub sizing bath should be kept at the minimum necessary to serve satisfactorily as a preservative of the glue.

\section{CONTENTS}

I. Introduction

II. Paper-making processes

III. Test methods

IV. Tests of paper-making fibers used.

V. Manufacturing details and test data for papers

1. Unsized papers

(a) Effect of beating on development of strength properties.

(b) Effect of beating on the alpha cellulose content and copper number

(c) Stability of unsized papers.

2. Beater-sized papers

(a) Rosin-sized .

(b) Starch-sized.-

3. Surface-sized papers VI. Acknowledgment

1 Research associate representing the Brown Co., Berlin, N.H. 


\section{INTRODUCTION}

The present report deals with a study of some effects of cellulosic impurities and paper-making processes on the strength and stability of sulphite bond papers. It is the second in a series of studies designed to extend present information relative to the paper-making value of various fibers. The purpose and plan of the investigation as a whole are stated more in detail in the previous article. ${ }^{2}$

The sulphite process consists, briefly, in cooking wood chips under pressure in a solution of calcium bisulphite containing uncombined sulphurous acid. Spruce is the wood generally employed, although hemlock is also well adapted to the process. Associated with the cellulose, which makes up about half of the raw wood, are incrusting materials such as lignins (to the extent of 25 or 30 percent), pentosans, gums, waxes, resins, etc. The hydrolytic action of the bisulphite liquor at high temperature and pressure renders the bulk of the impurities soluble so that they may be washed out. For the higher grades of papers the fibers are bleached to a white color by treatment with calcium hypochlorite.

Included in the present study are two types of commercial bleached sulphite pulp, one of domestic and the other of foreign make, prepared for manufacture of bond and ledger papers.

\section{PAPER-MAKING PROCESSES}

The methods of beating, paper-machine operation, and sizing followed very closely those described in the initial publication of this investigation, ${ }^{3}$ and in previous bureau publications. ${ }^{4}$ The reader is referred thereto for details of the operations.

\section{TEST METHODS}

In testing the papers produced the official paper testing methods of the Technical Association of the Pulp and Paper Industry were used for the determination of weight, bursting strength, thickness, folding endurance, tensile breaking strength, tearing strength, opacity, ash, resin, starch, and glue. ${ }^{5}$ The procedures for alpha cellulose content and copper number were described in detail in a previous publication. ${ }^{6}$ Determinations of the titratable acidity were made on extracts of ground paper (Kohler-Hall method) ${ }^{7}$ and directly on suspensions of the ground paper. Both procedures were outlined in a previous publication. ${ }^{8}$ The $\mathrm{pH}$ of the paper extracts was determined electrometrically using the quinhydrone electrode. The stability was measured by exposing the paper specimen under test to a current of air at $100^{\circ} \mathrm{C}$. for 72 hours and then determining to what extent the paper was altered in its properties, particularly

\footnotetext{
${ }^{2}$ R. H. Rasch, M. B. Shaw, and G. W. Bicking, Highly-Purified Wood Fibers as Paper-Making Material, B.S. Jour. Research, vol. 7 (RP372), pp. 765-782, November 1931 .

${ }^{3}$ See footnote 2.

4 M. B. Shaw and G. W. Bicking, Research on the Production of Currency Paper in the Bureau of Standards Experimental Paper Mill, B.S. Tech. Paper No. 329, and Further Experimental Production of Currency Paper in the Bureau of Standards Paper Mill, B.S. Jour. Research, vol. 3 (RP121), pp. 899-926, December 1929.

${ }_{5}$ Paper Testing Methods, prepared by the Committee on Paper Testing of the Technical Association of the Pulp and Paper Industry, Lockwood Trade J. Co., New York, 1929.

6 J. O. Burton and R. H. Rasch, The Determination of the Alpha Cellulose Content and Copper Num. ber of Paper, B.S. Jour. Research, vol. 6 (R P295), pp. 603-619, April 1931.

$7 \mathrm{~S}$. Kohler and G. Hall, Acidity in Paper, Paper Industry, vol. 7, pp. 1-5, October 1925.

8 R. H. Rasch, Accelerated Aging Test for Paper, B.S. Jour. Research, vol. 7 (RP352), pp. 465-475, September 1931 .
} 
folding endurance and alpha cellulose content. For more complete details the reader is referred to previous discussions of the method. ${ }^{910}$ The method used for determining pentosans was similar to the usual ones involving the distillation of the sample with dilute hydrochloric acid, except that precipitation was accomplished by the use of thiobarbituric acid instead of phloroglucinol. ${ }^{11}$

\section{TESTS OF PAPER-MAKING FIBERS USED}

Representative samples of the pulps used for this work were tested with results as given in table 1 . The pulps, which will be referred to throughout this paper as $\mathrm{A}$ and $\mathrm{B}$ are shown by the tests to be representative high-grade sulphite pulps. $\mathrm{A}$ is slightly better than $\mathrm{B}$ as regards content of alpha cellulose.

TABLE 1.-Tests of paper-making fibers used

\begin{tabular}{|c|c|c|c|c|c|}
\hline & $\begin{array}{l}\text { Alpha- } \\
\text { cellulose } \\
\text { content }\end{array}$ & $\begin{array}{l}\text { Copper } \\
\text { number }\end{array}$ & $\begin{array}{l}\text { Pento- } \\
\text { sans }\end{array}$ & Resin & Ash \\
\hline $\begin{array}{l}\text { Pulp A: } \\
\text { Original sample } \\
\text { Sample heated at } 100^{\circ} \mathrm{C} \text {. for } 72 \text { hours }\end{array}$ & $\begin{array}{r}\text { Percent } \\
184.6 \\
81.9\end{array}$ & $\begin{array}{l}3.10 \\
3.64\end{array}$ & $\begin{array}{r}\text { Percent } \\
3.50\end{array}$ & $\begin{array}{r}\text { Percent } \\
0.9\end{array}$ & $\begin{array}{l}\text { Percent } \\
0.22\end{array}$ \\
\hline $\begin{array}{l}\text { Pulp B: } \\
\text { Original sample. } \\
\text { Sample heated at } 100^{\circ} \mathrm{C} \text {. for } 72 \text { hours }\end{array}$ & $\begin{array}{r}182.4 \\
80.3\end{array}$ & $\begin{array}{l}3.20 \\
3.90\end{array}$ & 2.86 & .6 & .19 \\
\hline
\end{tabular}

1 The same determination made on 1/4-inch squares of the pulp sheet gave a result of 85.9 and 83.8 percent, respectively. Many methods for the determination of alpha-cellulose content, including the tentative standard method of the American Chemical Society, specify that the sample shall be in the form of squares.

\section{MANUFACTURING DETAILS AND TEST DATA FOR PAPERS}

\section{UNSIZED PAPERS}

(a) EFFECT OF BEATING ON DEVELOPMENT OF STRENGTH PROPERTIES

The general method of beating characterized by a gradual lowering of the beater roll has been described in detail in earlier publications.12 This procedure, so advantageous in the development of high-strength currency paper, was deemed to be equally applicable in obtaining optimum results with the sulphite pulps under study. Beating is one of the most important operations in paper making. The duration of beating and the manipulation of the beater roll are among the variables in the beating operation which have their marked effect on the physical properties of the paper, such as strength, opacity, hardness, etc. This is especially true of sulphite fibers which "hydrate" with comparative ease. Overbeating results in a sheet of low tearing strength and low opacity, and also effects an undesirable hardness or "tinny" character in the sheet. Underbeating results in a soft, bulky, weak sheet of poor formation.

The effect of duration of beating was studied both with hand sheets and with the paper machine product. Hand sheets were made from

${ }^{9}$ See footnote 2, p. 8 , and footnote 8, p. 8 .

10 R. H. Rasch, G. O. Stone, Procedure for Estimation of Stability of Paper by Heating, Paper Trade J., vol. 95 , no. 4 , pp. $40-42$, July $28,1932$.

11 Dox and Plaisance, J. Am. Chem. Soc., vol. 38, p. 2156, 1926.

12 See footnote 4, p. 8. 
stock taken at different intervals during the beatings and were tested for strength. ${ }^{13}$

Typical illustrations are given in figure 1 of the effect of beating on the folding endurance, tearing strength, and bursting strength. It is apparent that $\mathrm{A}$ attains maximum folding endurance in about 6 hours and B in 5 hours. The bursting strength develops in similar fashion. Beginning at an early stage in the beating the tearing strength decreases gradually with further beating.

Unsized papers were made on the paper machine from fibers beaten 4,5 , and 7 hours, respectively. The data relative to the operation of the beater and the test results of the machine-made papers are given in tables 2 and 3 . In the case of both pulps 7 hours was considered too long. A 4-hour beating of pulp A gave the best result as

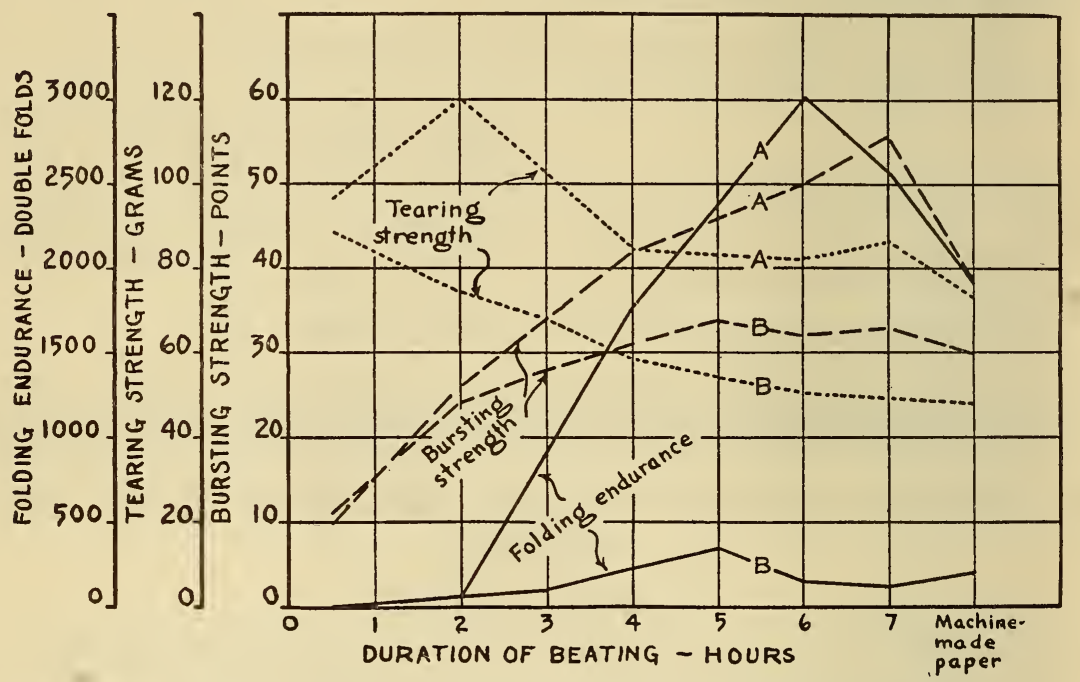

FIGURE 1.-Strength properties of hand sheets of sulphite fibers.

regards opacity, feel, and general appearance. A 5-hour beating with less drastic roll setting was judged to be more advantageous in the case of pulp B, which was somewhat less susceptible to "hydration."

The schedule of roll settings adopted for the beatings is given in table 4 . In each case the treatment as outlined therein was followed by a light brushing in the Jordan.

The papers made from pulp A are very high in folding endurance for this type of fiber. Otherwise the papers made from pulps A and B approximate in strength the average commercial sulphite bonds.

Figures 2 and 3 are photomicrographs of the beaten fibers and are of interest in illustrating the differences in the two pulps. Figure 2 shows the fibers of pulp A, which are long, clean, and uniform in comparison to those of pulp B (fig. 3). In the latter case the shrunken and shriveled appearance of many of the fibers is noteworthy. Fibrillae can be seen on the fibers in both figures. 


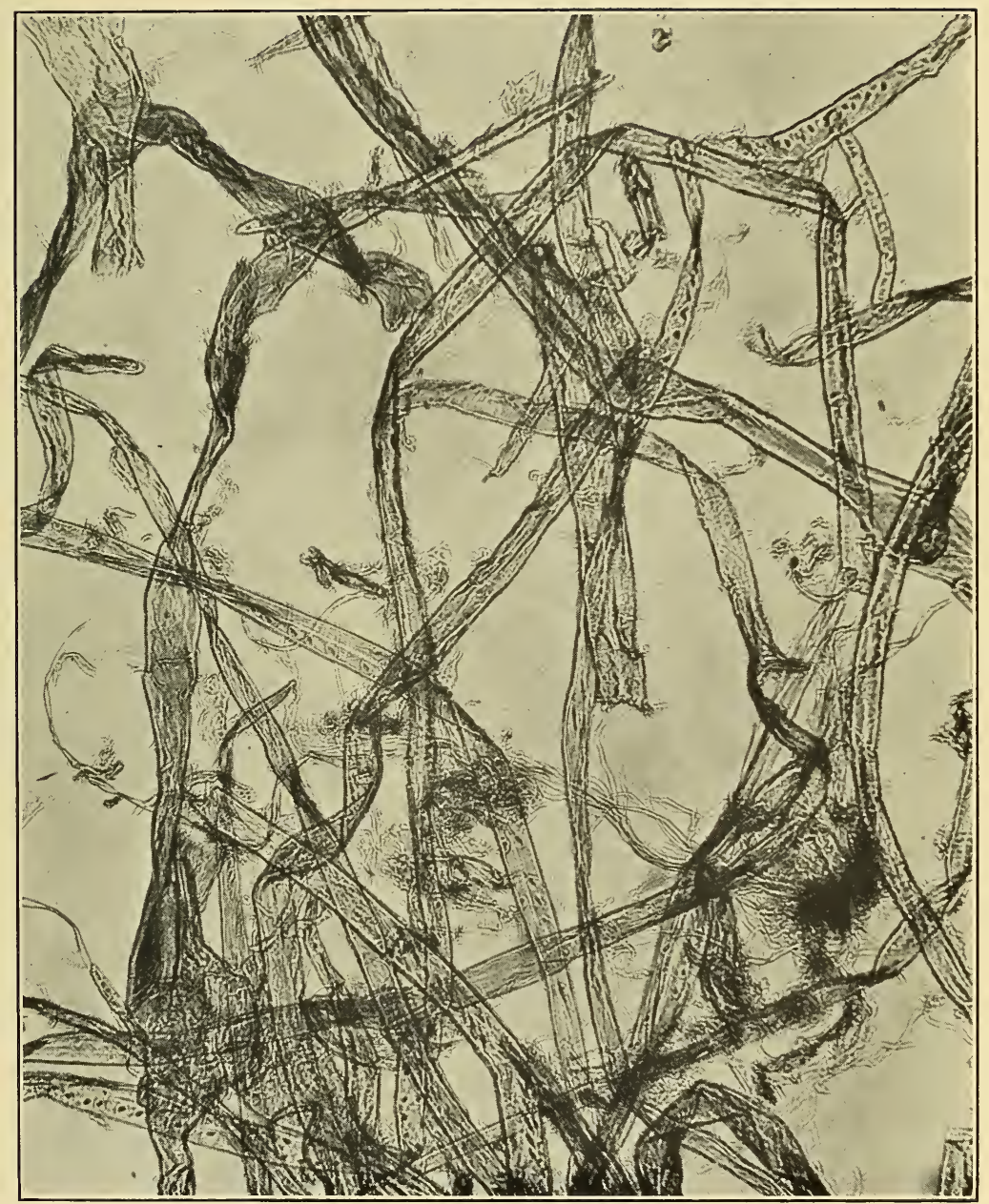

Figure 2.-Sulphite wood fiber A. $\times 100$. 
B.S. Journal of Research, RP574

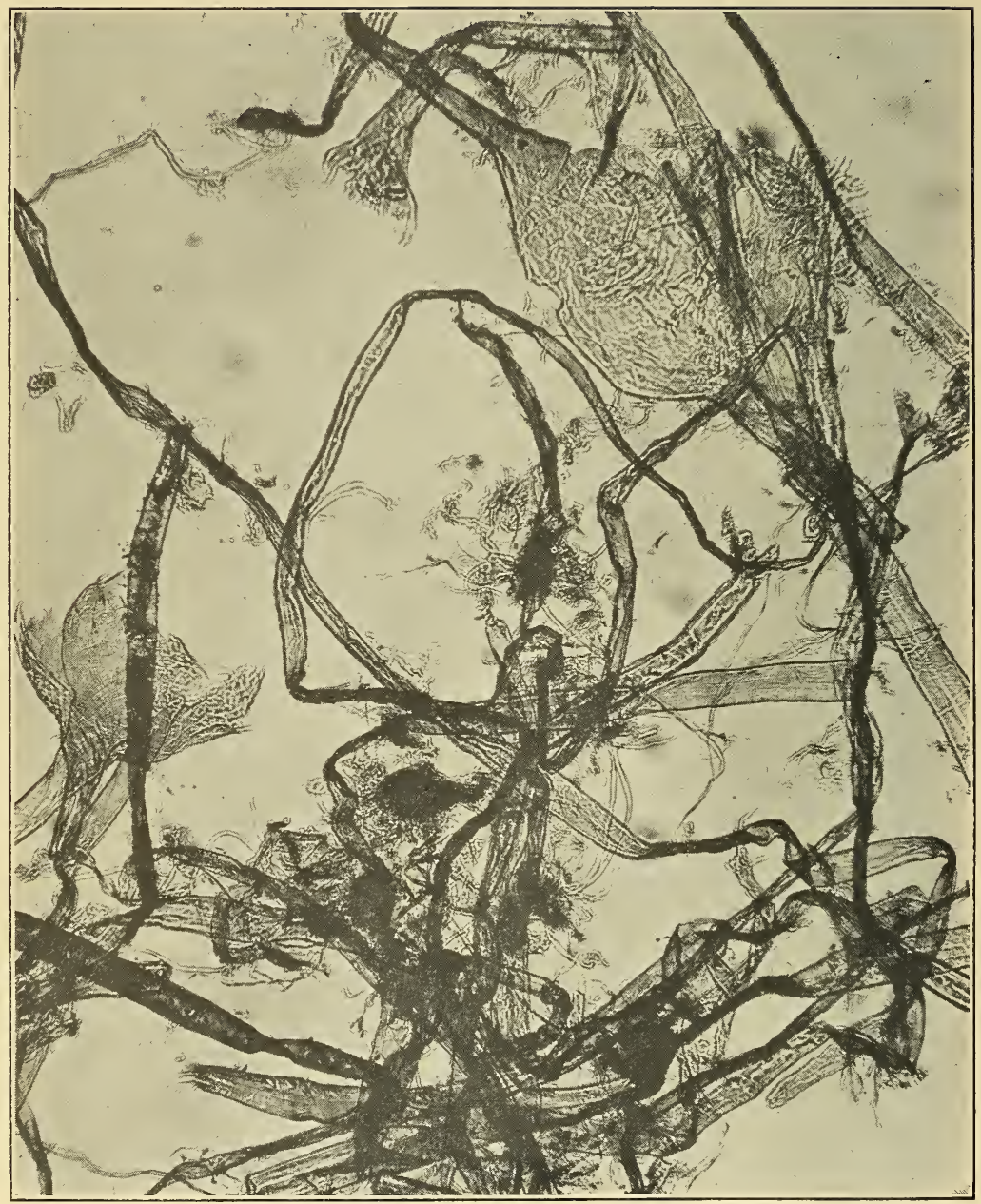

Figure 3.-Sulphite wood fiber B. $\times 100$. 


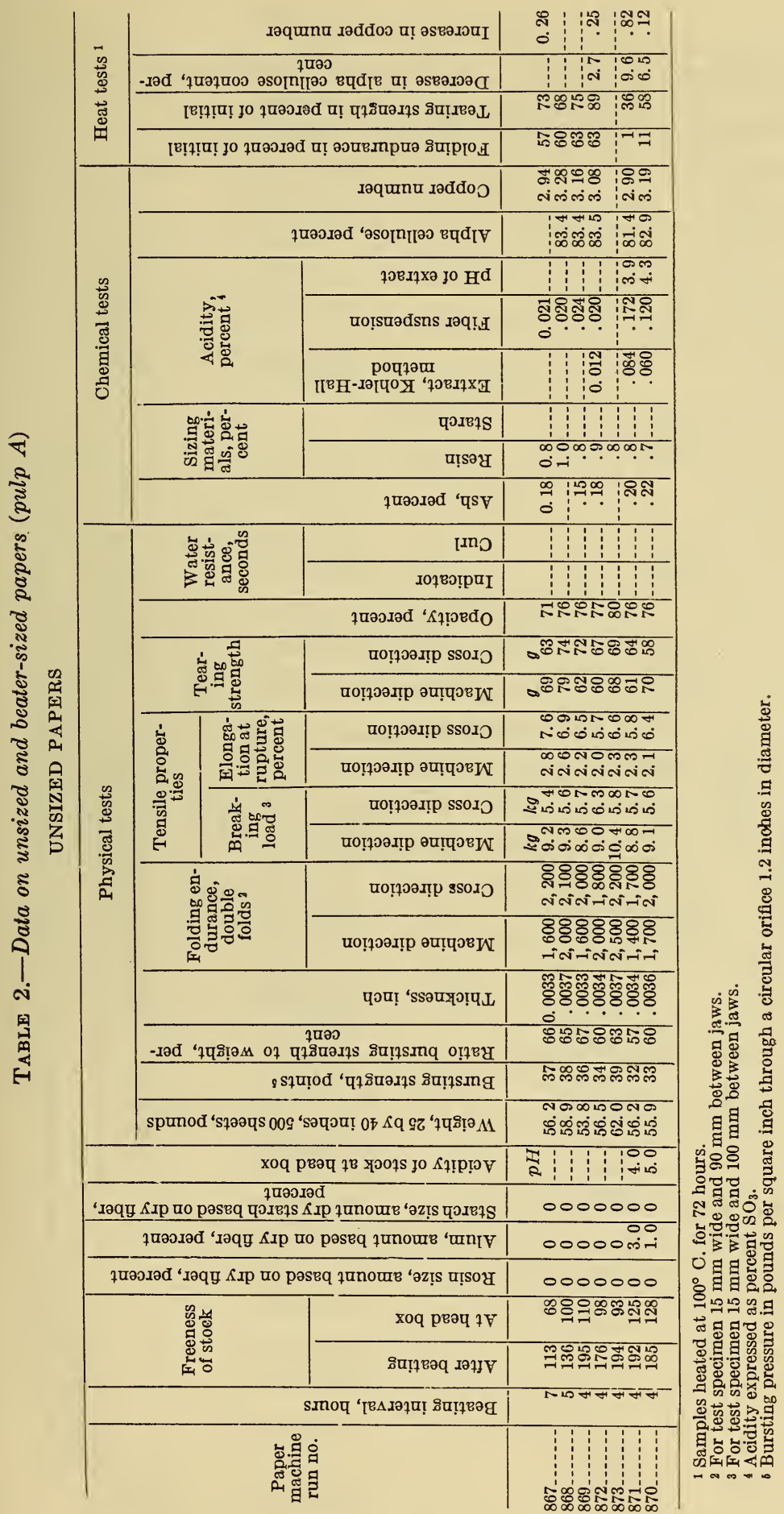




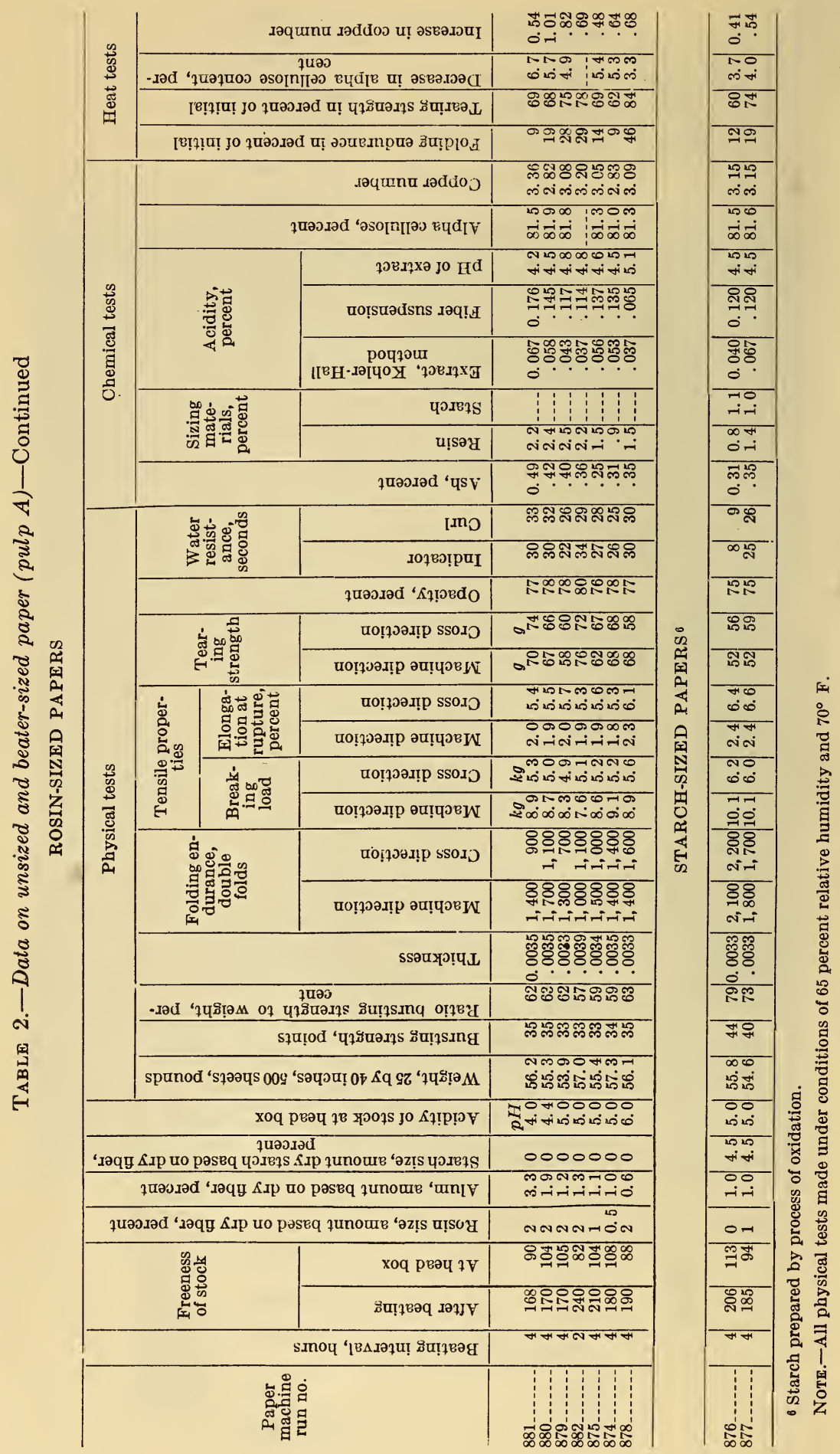




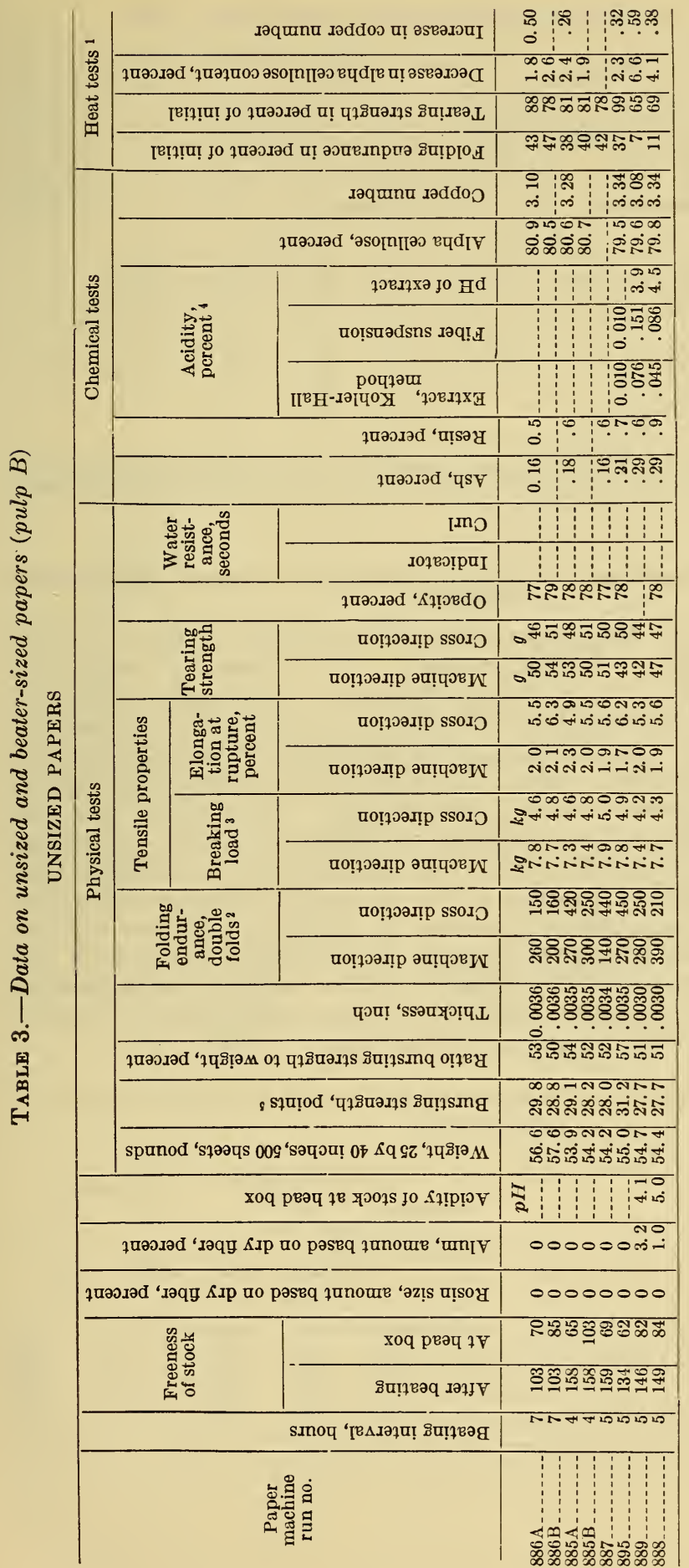
0 ......... H120000020

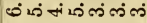

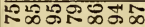

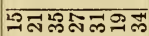
정재욤ㅇㅇ

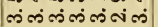
तन0ONमा

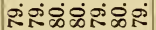

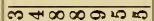
मं मं सं सं संखि

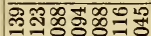
ठ

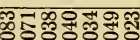
○े

400m000

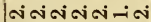

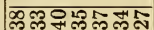
ठ

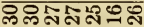

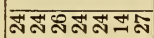

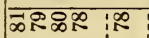

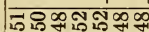

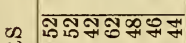
庄 $\circ$ ซี \&

$\infty 000 \infty 0$

बनल लबत

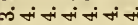
7ODONN

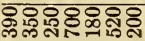

=00020 70

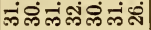
काल्लनलन

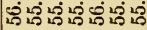
\#00000 सं सं $2 \sin ^{\circ} 2 \sin ^{\circ} 0^{\circ}$ न०समलतन

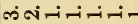
12

NNNNП0์

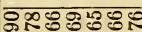

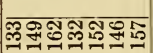


TABLE 4.-Schedule of roll settings for beating sulphite pulps

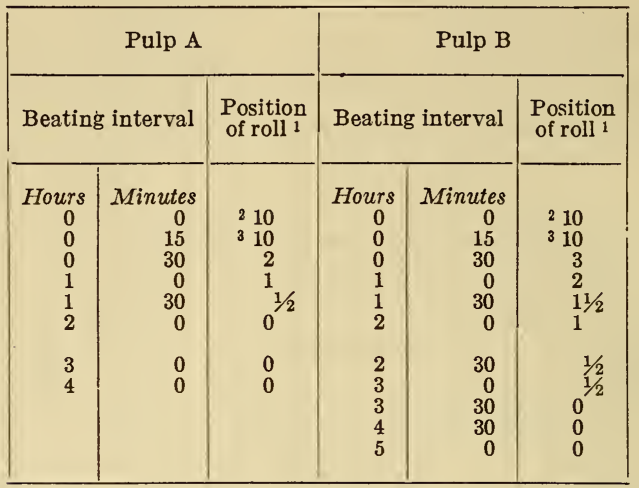

1 Indicated as turns of the handwheel with which the position of the roll relative to the bed plate is changed. At the zero setting the bed plate is just barely cleared. One turn of the handwheel raises or lowers the roll 0.008 inch.

2 Lighter-bar up.

3 Lighter-bar down.

\section{(b) EFFECT OF BEATING ON THE ALPHA CELLULOSE CONTENT AND COPPER}

The pulp used for this experiment, while neither A nor B, was a sulphite pulp similar to B in all respects. A 2 percent suspension of fibers was beaten in a small laboratory beater. Portions of the stock were taken out at the following intervals: (1) after a brief slushing, (2) after $2 \frac{1 / 4}{4}$ hours of beating, (3) after $4 \frac{1}{4}$ hours of beating, and (4) after $6 \frac{1}{4}$ hours of beating. Hand sheets were made from each of these portions and air dried at room temperature. The alpha cellulose content was determined on squares of the sheets, also on ground specimens. The data, which are presented in table 5, indicate that the beating caused little change in the chemical properties measured by these tests. The apparent increase in the alpha cellulose content of the squares with increased duration of beating is a result of decreased absorptiveness of the sheet and thus incomplete extraction by the mercerizing solution, which is further evidence of the desirability of grinding pulp specimens for this test.

TABLE 5.-Effect of beating on the alpha cellulose content and copper number of a sulphite pulp ${ }^{1}$

\begin{tabular}{|c|c|c|c|c|c|}
\hline \multirow{2}{*}{ Sample } & \multirow{2}{*}{$\begin{array}{c}\text { Duration } \\
\text { of beat- } \\
\text { ing }\end{array}$} & \multicolumn{2}{|c|}{$\begin{array}{l}\text { Alpha cellulose } \\
\text { content }\end{array}$} & \multicolumn{2}{|c|}{ Copper number } \\
\hline & & $\begin{array}{l}1 / 4 \text {-inch } \\
\text { squares }\end{array}$ & $\begin{array}{c}\text { Ground } \\
\text { fiber }\end{array}$ & $\begin{array}{l}1 / 4 \text {-inch } \\
\text { squares }\end{array}$ & $\begin{array}{l}\text { Ground } \\
\text { fiber }\end{array}$ \\
\hline 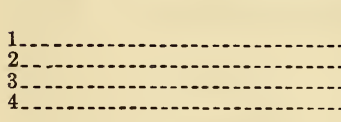 & $\begin{array}{r}\text { Hours } \\
0 \\
21 / 4 \\
41 / 4 \\
61 / 4\end{array}$ & $\begin{array}{r}\text { Percent } \\
84.3 \\
86.1 \\
88.0 \\
88.8\end{array}$ & $\begin{array}{r}\text { Percent } \\
81.8 \\
80.4 \\
80.2 \\
80.8\end{array}$ & $\begin{array}{l}3.34 \\
3.34 \\
3.33 \\
3.35\end{array}$ & $\begin{array}{l}3.45 \\
3.31 \\
3.31 \\
3.07\end{array}$ \\
\hline
\end{tabular}

1 The beating was done in a laboratory beater. 
(c) STABILITY OF UNSIZED PAPERS

The effect of beating on the stability of the paper was studied. Hand sheets were made from stock beaten to various extents in the beater used for machine runs. Folding endurance was determined on hand sheets heated for 72 hours at $100^{\circ} \mathrm{C}$. and on the unheated paper according to the usual procedure. The data obtained are presented in figure 4 for pulps beaten up to the points of maximum

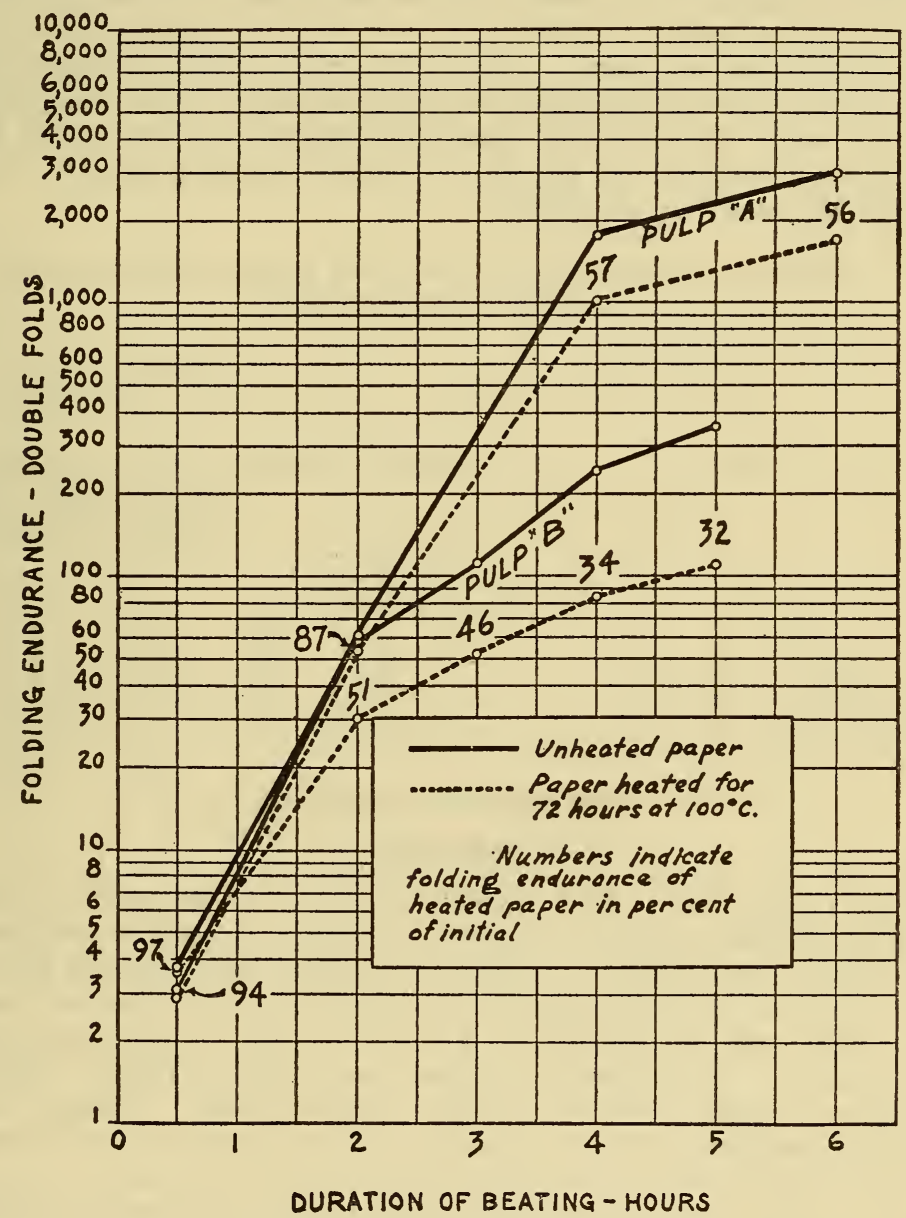

FIGURE 4.-Effect of beating on stability of sulphite fibers

folding endurance. The hand-made papers prepared from pulps beaten only one half hour undergo no appreciable change on heating, whereas those prepared from pulps beaten up to maximum strength decrease in folding endurance to 56 percent of initial, for pulp A, and to 32 percent of initial, for pulp B, as a result of the heat treatment. The results are in substantial agreement with those of similar experiments made by Richter. ${ }^{14}$

${ }^{14}$ Durability of Purified Wood Fibers, Ind. Eng. Chem., vol. 23, no. 4, pp. 371-380, A pril 1931. 176983-33-2 
In regard to the stability of unsized machine-made papers, it will be noted in tables 2 and 3 that the paper made from pulp A retained about 60 percent of the initial folding endurance after the heat treatment, and that the paper made from pulp B retained about 40 percent. Varying the beating time at 4,5 , and 7 hours, respectively, resulted in no apparent effect on the stability. Unsized papers made from either fiber lost 2 to 3 percent in alpha cellulose content under the heat test. In table 6 comparison is made of the chemical purity and stability of the papers made from the sulphite pulps with unsized papers made in the Bureau mill from various fibers of higher commercial grade. It is clear that the sulphite papers were considerably less stable under the heat test than those made from the purer fibers. This is further evidence of the close relation between purity of paper fibers and the stability of papers.

TABLE 6.-Stability of unsized papers made from sulphite pulps and from fibers of higher commercial grade

\begin{tabular}{|c|c|c|c|c|c|}
\hline \multirow[b]{2}{*}{ Fiber } & \multirow[b]{2}{*}{$\begin{array}{c}\text { Alpha } \\
\text { cellulose }\end{array}$} & \multirow[b]{2}{*}{$\begin{array}{l}\text { Copper } \\
\text { number }\end{array}$} & \multicolumn{3}{|c|}{$\begin{array}{l}\text { After heat treatment at } 100^{\circ} \mathrm{C} . \\
\text { for } 72 \text { hours }\end{array}$} \\
\hline & & & $\begin{array}{l}\text { Folding } \\
\text { endur- } \\
\text { ance in } \\
\text { percent } \\
\text { of initial }\end{array}$ & $\begin{array}{l}\text { Decrease } \\
\text { in alpha } \\
\text { cellulose } \\
\text { content }\end{array}$ & $\begin{array}{c}\text { Increase } \\
\text { in copper } \\
\text { number }\end{array}$ \\
\hline $\begin{array}{l}\text { Fiber A A } \\
\text { Fiber B B } \\
\text { Fiber C } \\
\text { Sulphite wood fiber A } \\
\text { Sulphite wood fiber B }\end{array}$ & $\begin{array}{r}\text { Percent } \\
97.7 \\
93.4 \\
91.5 \\
83.5 \\
79.5\end{array}$ & $\begin{array}{r}0.29 \\
.62 \\
.65 \\
3.08 \\
3.34\end{array}$ & $\begin{array}{l}95 \\
97 \\
99 \\
58 \\
37\end{array}$ & $\begin{array}{r}0.6 \\
.8 \\
.4 \\
2.7 \\
2.3\end{array}$ & $\begin{array}{l}0.05 \\
.09 \\
.15 \\
.25 \\
.32\end{array}$ \\
\hline
\end{tabular}

\section{BEATER-SIZED PAPERS}

(a) ROSIN-SIZED

In order to study the effect of rosin sizing on the properties of papers made from sulphite fiber a number of machine runs were made in which acidity and amount of rosin sizing used were varied while the factors involved in the mechanical operation of the beater, such as beating time and manipulation of the roll, were, as far as possible, kept constant. As controls for the rosin-sized papers, runs were made using varying amounts of alum and no rosin. Tables 2 and 3 contain the pertinent paper-making data and the results of tests of the papers produced.

In run no. 881 a large excess of alum over that required for adequate sizing was purposely added. The $\mathrm{pH}$ of this paper was 4.2. A very adverse effect on stability, as regards decrease in folding endurance and alpha cellulose content under the heat test occurred. Reduction in the use of alum resulted in the expected improvements in stability. For example, in run no. 878 , in which only 0.6 percent alum was employed, the stability of the rosin-sized paper approached closely to that of the paper containing neither rosin nor alum. This paper, having a $\mathrm{pH}$ value of 5.1, was fairly well sized; however, it is believed that about 1.0 percent alum would be a safer amount to use. With this fiber, as with the purer wood fibers previously studied, $\mathrm{pH} 5.0$ 
appears to be about the correct acidity for maximum stability consistent with adequate sizing.

No very marked difference in stability could be detected among the papers sized with different amounts of rosin. It is clear, however, that the rosin-sized papers were more stable toward heat than papers of corresponding acidities containing no rosin. This finding is contrary to that made in the study of the purer wood fibers, since rosinsized papers made from those fibers were less stable than the unsized papers..$^{15}$ As a possible reason for this apparent disagreement, it is suggested that below a certain stability range rosin sizing may actually have a protective effect, similar to that of glue in surface sizing, which more than offsets an accompanying deteriorative effect. The indi-

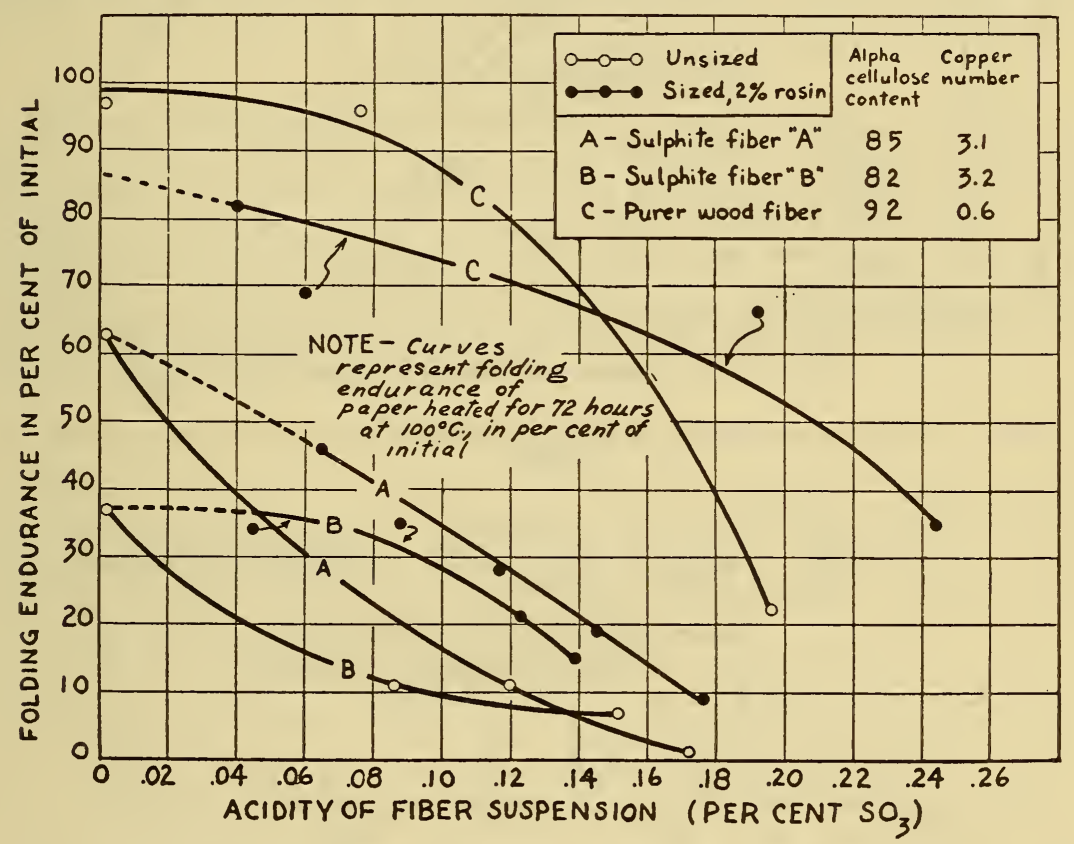

FIGURE 5.-Effect of acidity of unsized and rosin-sized sulphite bond papers on stability.

cations are that, within the range studied (one half to 2 percent), the amount of rosin employed in sizing sulphite papers is not an important consideration as far as stability is concerned.

The same experiments in varying rosin size and acidity were made using pulp B. The data relative to the preparation and tests of papers made from this pulp are given in table 3 . Results as to the effect of acid and rosin on the stability of papers made with pulp B agree in most particulars with those for pulp A papers.

Figures 5 and 6 are of interest in illustrating some of the points brought up in the above paragraphs. They show the effects of acidity (fiber-suspension method), rosin, and the quality of the fibrous raw material on the stability of the papers produced.

15 See footnote 2, p. 8 . 


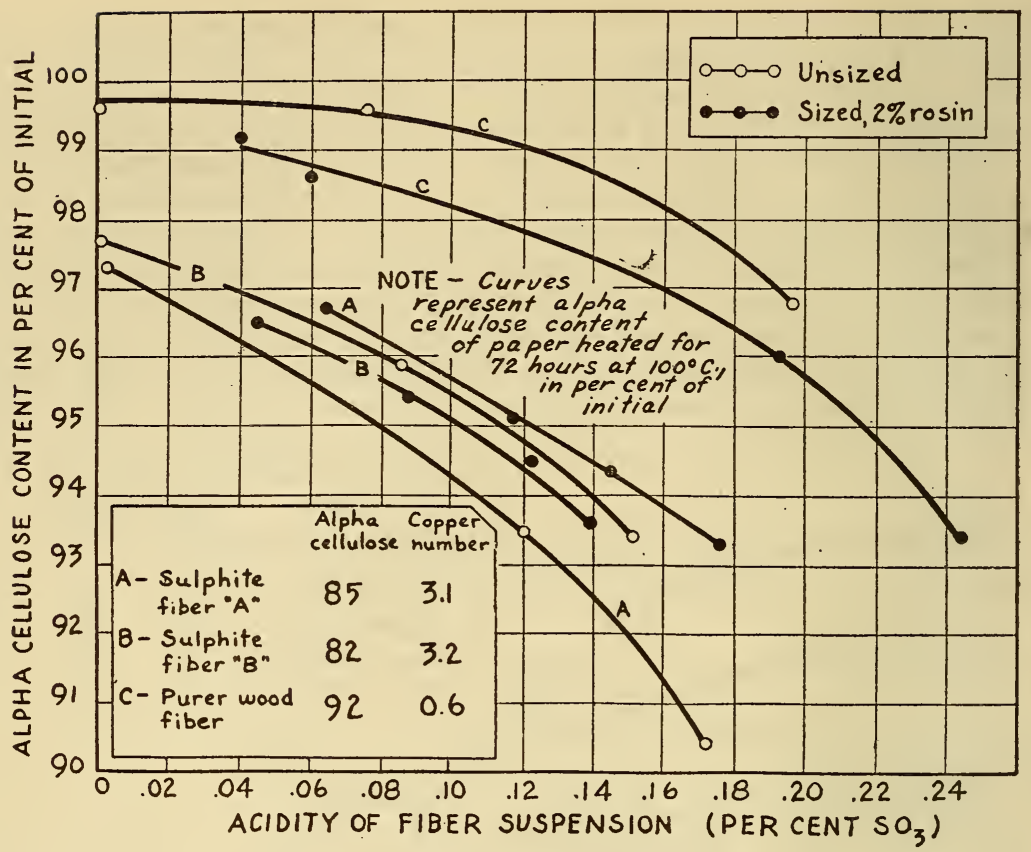

FIGURE 6.-Effect of acidity of unsized and rosin-sized sulphite bond papers on stability.

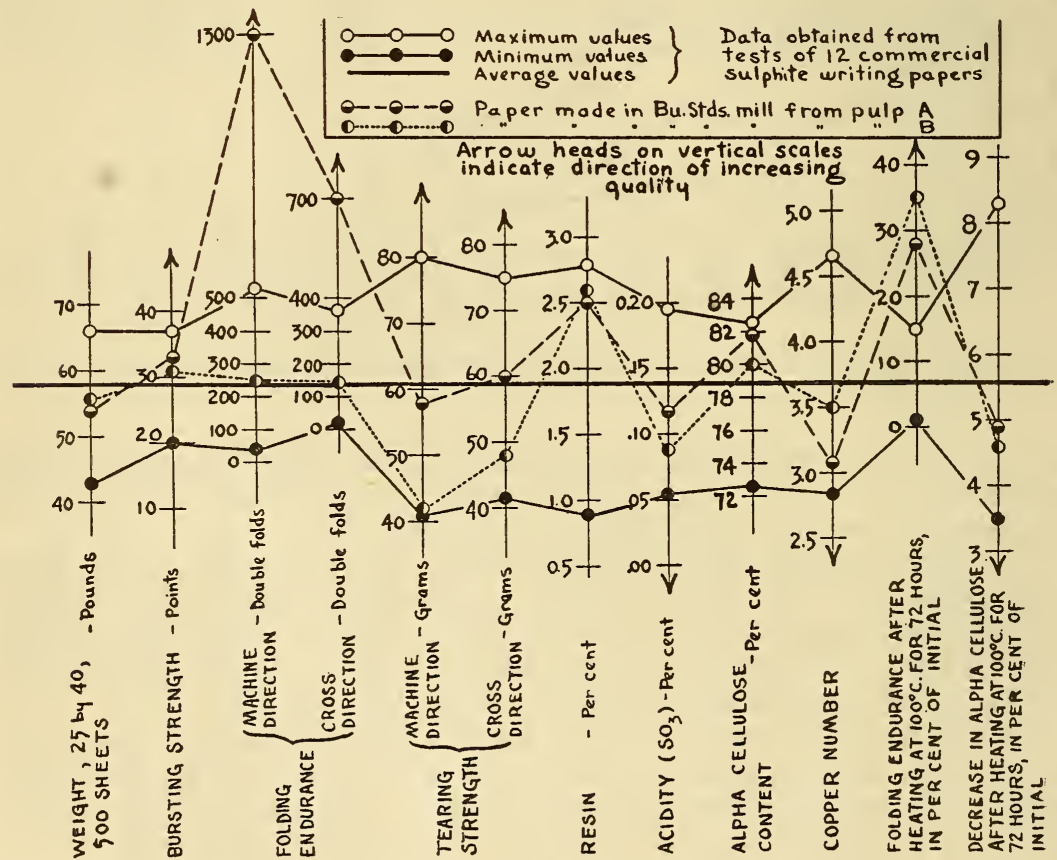

FIGURE 7.-Comparison of tests of commercial sulphite writing papers with tests of experimental papers. 
Figure 7 is of interest in affording a comparison of the strength, chemical purity, and stability of two rosin-sized papers made in the Bureau mill from pulps $A$ and $B$ with the maximum, minimum, and average values selected from the tests of 12 different commercial, rosin-sized sulphite papers. With the exception of the folding endurance of the paper made from pulp $\mathrm{A}$, which is very high, the strength tests of the experimental papers are in good agreement with those of the average commercial papers. In regard to acidity, however, it should be pointed out that the average commercial sheet has an acidity of 0.14 percent $\mathrm{SO}_{3}$. This is unnecessarily high and is reflected in the poorer stability of the commercial paper as compared with the experimental paper having optimum acidity. The alpha cellulose content and copper number tests indicate that the experimental sheets have a higher chemical purity than the average commercial papers.

\section{(b) STARCH-SIZED}

Two runs were made in which starch, manufactured commercially by a so-called oxidation process, was added to the beater. In one case rosin size was not used and in the other case 1 percent was employed. The data relative to these papers are given in table 2 . The retention of starch was rather low, amounting to about a fourth of that added to the beater, but improvements in folding endurance and tensile properties were realized. The presence of starch did not adversely affect the stability of the papers.

\section{SURFACE-SIZED PAPERS}

Three different basic papers were used for the tub sizing experiments, an unsized paper containing no alum, and two papers sized respectively with one half and 1 percent rosin. The acidity sought in the case of the rosin-sized base papers was $\mathrm{pH}$ 5.0. On test, however, they were found to be somewhat more acid. This fact is to be considered in connection with the stability of these papers. Papers made from pulp A were sized, respectively, with glue, glue containing alum, and starch containing alum. Papers made from pulp B were sized with glue containing alum. Data relative to the preparation and testing of these papers are given in table 7. Control samples corresponding to each of the surface sizing runs were tested individually for strength and stability. The control samples were taken immediately before and after each surface sizing treatment so as to be as representative as possible of the portion of paper sized. 


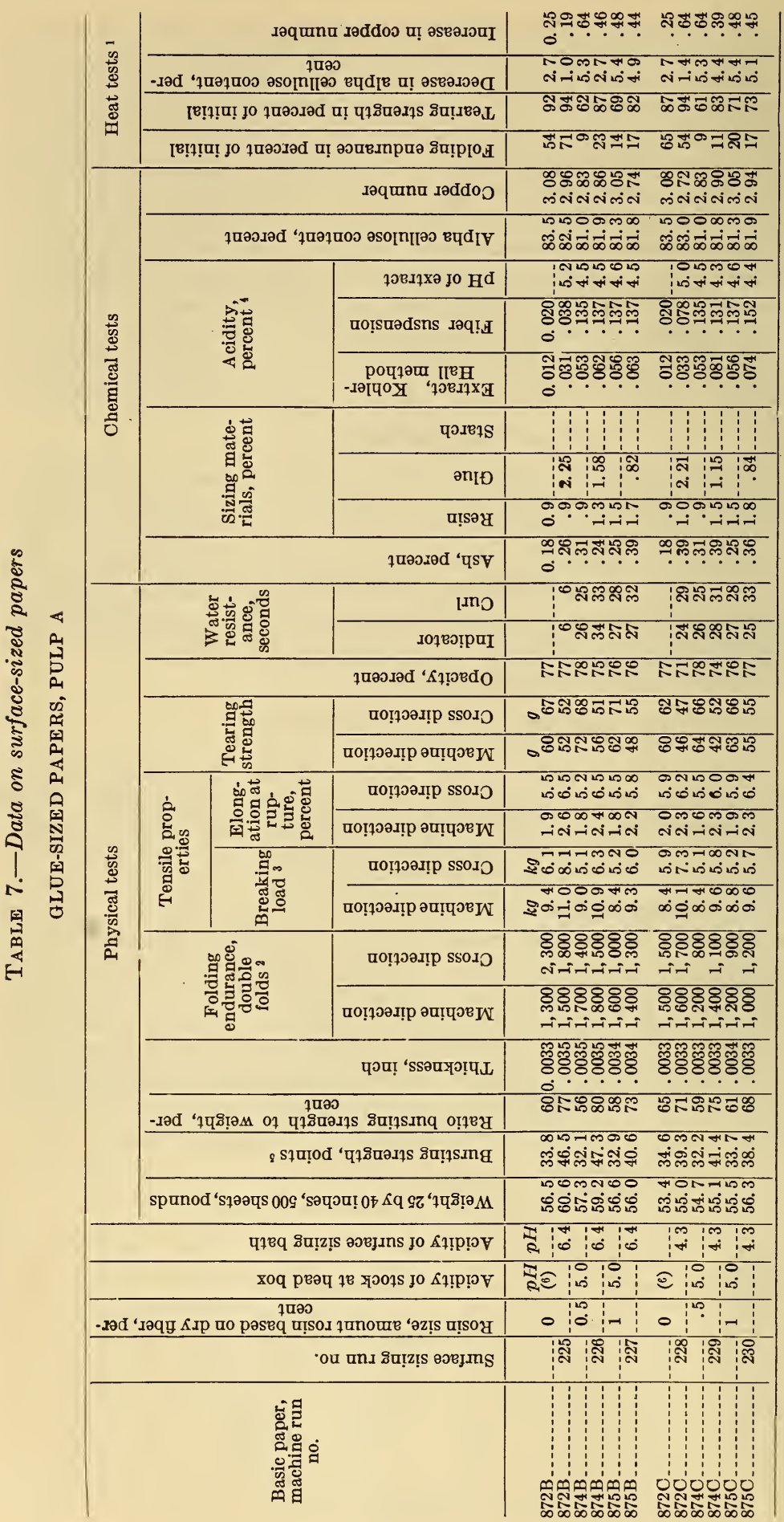




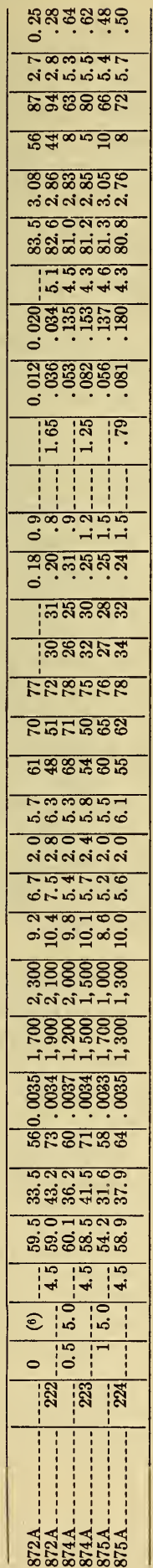

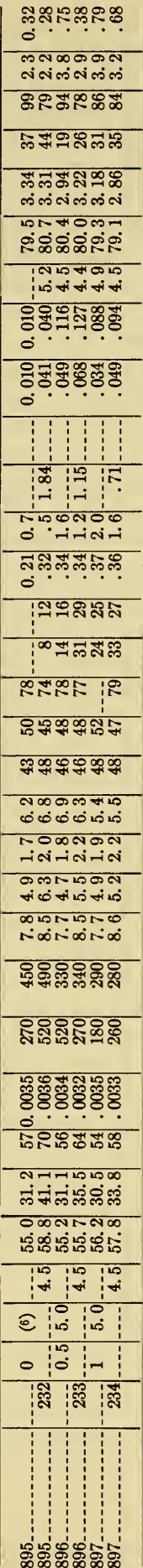


In general, surface sizing resulted in marked improvement in tensile properties, the magnitude of which was roughly related to the amount of glue or starch taken up on sizing. No great improvement in folding endurance resulted. Of the 12 papers, 5 showed no improvement in this respect, while only 4 showed an increase of 10 percent or more. The tearing strength of papers made from pulp A was lowered about 20 percent by the surface sizing. Papers made from pulp B, having a very low tearing strength initially, were unchanged by sizing. The uniformity of the paper in respect of folding endurance in the two directions was improved very greatly by surface sizing. On the average, the values for the folding endurance in the machine and cross directions differed from each other, in the case of the basic papers, by about 40 percent. This difference was reduced to 12 percent on surface sizing. In regard to effects of sizing materials on the strength of papers, the characteristics of the fibers or papers treated should be considered. For example, it is known that while the folding endurance of weak rag papers may be materially increased by surface sizing them, such treatment may decrease the folding endurance of very strong rag papers. Therefore, other sulphite fibers of different characteristics from those used in this study might react differently to sizing treatments as far as strength is concerned.

All the papers of the series were relatively low in stability, with the exception of tub sizing run no. 225, a waterleaf sheet sized with glue containing no alum, which retained 71 percent of the initial folding endurance and decreased but 1 percent in alpha cellulose content after the accelerated aging test. In general, the papers engine sized with rosin and surface sized with glue lost considerably over half of the initial folding endurance and decreased several percent in alpha cellulose content. These are indications of only moderately stable paper. A slight improvement in stability resulted from surface sizing with glue. Starch sizing apparently offered no improvement in stability. When alum was not used in the sizing bath the papers appeared to be slightly more stable than when it was present.

The results of this study are further evidence of the close relation between the cellulosic purity of paper fibers and the stability of papers; the moderate stability of the best papers produced was commensurate with the medium degree to which the fibers had been purified. Under a system of classification of printing and writing papers, relative to their permanence qualities, which has been suggested by the Bureau of Standards, the best of the sulphite papers produced in this study would fall in class III, as representative of papers of fair purity for routine correspondence and other records requiring moderate life. ${ }^{16}$

Since some of the various types of fibers included in the program of study may have certain inherent characteristics that would make them adapted to the manufacture of currency paper, it is planned to make currency-type papers from each of them so that their printing and wearing properties may be studied and compared. In table 8 test results for waterleaf and glue-sized papers are given for currency-type paper made from the stronger of the two sulphite fibers discussed in this article. While the papers are of very high strength, they do not meet the United States Government strength requirements for currency paper.

16 B. W. Scribner, Permanence Standards for Printing and Writing Papers, Trans. A.S.M.E., vol. 52, no. 19, P.I., pp. 52-55, May-August 1930. Also, Paper Mill and Wood Pulp News, vol. 53, p. 13, June $21,1930$. 
TABLE 8.-Tests of currency-type papers made from sulphite fibers

\begin{tabular}{|c|c|c|}
\hline Paper machine run no & 873 & 873 \\
\hline $\begin{array}{l}\text { Surface sizing run no } \\
\text { Weight ( } 500 \text { sheets } 17 \text { by } 22 \text { inches) }\end{array}$ & 23.2 & $\begin{array}{r}231 \\
23.4\end{array}$ \\
\hline Weight ( 500 sheets 25 by 40 inches) $\ldots$ & 62.0 & 62.5 \\
\hline Thickness & 0.0037 & 0.0036 \\
\hline Bursting strength.............. & 39.1 & 50.4 \\
\hline Folding endurance: & & \\
\hline $\begin{array}{l}\text { Machine direction } \\
\text { Cross direction }\end{array}$ & $\begin{array}{l}2,500 \\
2,200\end{array}$ & $\begin{array}{l}2,200 \\
2,400\end{array}$ \\
\hline Tearing strength: & & \\
\hline Machine direction. & 68 & 53 \\
\hline Cross direction. & 69 & 52 \\
\hline Glue & 0 & 1. 96 \\
\hline 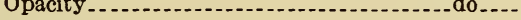 & 80.0 & 77.0 \\
\hline
\end{tabular}

1 Approximately pounds per square inch.

\section{ACKNOWLEDGMENT}

The authors are indebted to M. J. O'Leary ${ }^{17}$ and G. O. Stone ${ }^{18}$ for assistance in these studies.

Washington, April 27, 1933.

17 Assistant paper maker.

18 Assistant research associate representing the National Research Council. 